\title{
Article \\ Social Determinants of Cigarette Smoking among American Women during Pregnancy
}

\author{
Shervin Assari $1,2, *$ (i) and Shanika Boyce ${ }^{3}$ (i) \\ 1 Department of Family Medicine, Charles R Drew University of Medicine and Science, \\ Los Angeles, CA 90059, USA \\ 2 Department of Urban Public Health, Charles R Drew University of Medicine and Science, \\ Los Angeles, CA 90059, USA \\ 3 Department of Pediatrics, Charles R Drew University of Medicine and Science, Los Angeles, CA 90059, USA; \\ shanikaboyce@cdrewu.edu \\ * Correspondence: assari@umich.edu; Tel.: +1-323-563-4800
}

Citation: Assari, S.; Boyce, S. Social Determinants of Cigarette Smoking among American Women during Pregnancy. Women 2021, 1, 128-136. https://doi.org/10.3390/ women1030012

Academic Editors: Edward Araujo Júnior and Mary V. Seeman

Received: 9 March 2021

Accepted: 13 July 2021

Published: 15 July 2021

Publisher's Note: MDPI stays neutral with regard to jurisdictional claims in published maps and institutional affiliations.

Copyright: (c) 2021 by the authors. Licensee MDPI, Basel, Switzerland. This article is an open access article distributed under the terms and conditions of the Creative Commons Attribution (CC BY) license (https:// creativecommons.org/licenses/by/ $4.0 /)$.

\begin{abstract}
Educational attainment is among the most substantial protective factors against cigarette smoking, including during pregnancy. Although Minorities' Diminished Returns (MDRs) of educational attainment, defined as weaker protective effect of education for racial and ethnic minority groups compared to Non-Hispanic Whites, has been demonstrated in previous studies; such MDRs are not tested for cigarette smoking during pregnancy. To better understand the relevance of MDRs to tobacco use during pregnancy, this study had three aims: firstly, to investigate the association between educational attainment and cigarette smoking in pregnant women; secondly, to compare racial and ethnic groups for the association between educational attainment and cigarette smoking; and thirdly, to explore the mediating effect of poverty status on such MDRs, among American adults during pregnancy. This cross-sectional study explored a nationally representative sample of pregnant American women $(\mathrm{n}=338)$, which was taken from the Population Assessment of Tobacco and Health (PATH; 2013). Current smoking was the outcome. Educational attainment was the independent variable. Region and age were the covariates. Poverty status was the mediator. Race and ethnicity were the effect modifiers. Overall, a higher level of educational attainment $(\mathrm{OR}=0.54, p<0.05)$ was associated with lower odds of current smoking among pregnant women. Race $(\mathrm{OR}=2.04, p<0.05)$ and ethnicity $(\mathrm{OR}=2.12, p<0.05)$ both showed significant interactions with educational attainment on smoking, suggesting that the protective effect of educational attainment against smoking during pregnancy is smaller for Blacks and Hispanics than Non-Hispanic Whites. Poverty status fully mediated the above interactions. In the United States, highly educated pregnant Black and Hispanic women remain at higher risk of smoking cigarettes, possibly because they are more likely to live in poverty, compared to their White counterparts. The results suggest the role that labor market discrimination has in explaining lower returns of educational attainment in terms of less cigarette smoking by racial and ethnic minority pregnant women.
\end{abstract}

Keywords: social determinants of health; ethnicity; race; Hispanics; population groups; poverty; socioeconomic status; tobacco use; smoking

\section{Background}

Smoking cigarettes during pregnancy is probably the single most important preventable cause of adverse outcomes for pregnant woman [1,2] and the unborn child [3-5]. Studies that have compared various risk factors in the perinatal period have suggested that exposure to tobacco smoke should be regarded as one of the most harmful exposures that increase short- and long-term morbidity and mortality for both mothers and children [6,7]. Smoking cigarettes during pregnancy increases the risks of developing congenital disabilities and poor pregnancy outcomes $[6,7]$. 
Smoking cigarettes during pregnancy is linked to a variety of adverse pregnancy and birth outcomes [8-10]. Prenatal cigarette smoking disturbs the equilibrium between the oxidant and the antioxidant systems, resulting in several adverse effects at the genetic and cellular levels linked to a large number of diseases in the unborn child [11]. The tobacco-induced harm to the unborn offspring manifests itself at various times in life, from birth to death; many harmful consequences do not have known treatments [12].

Similar to the social inequalities in health [13,14], and tobacco use [15], racial/ethnic minority status [16-20] and socioeconomic status (SES) [21-25] are strong social determinants of smoking during pregnancy. Black and Hispanic women may also be at high risk of smoking during pregnancy $[1,8,26]$. High educational attainment is a robust protective factor against smoking for pregnant women $[3,21,23,27-30]$. Poverty status is also another determinant of smoking during pregnancy $[16,18,26,31]$. Correlates of smoking during pregnancy, however, differ between Whites and Non-Whites [1,26,32].

Recent research on the Minorities' Diminished Returns (MDRs) phenomenon has proposed diminished returns of educational attainment [33] as an essential but historically neglected mechanism for racial and ethnic disparities in tobacco burden in the United States [34,35]. Accordingly, at least some of the racial/ethnic tobacco use disparities are because of "less than expected" protective effects of SES indicators on tobacco use for minority populations [34,35]. This model suggests that: (a) tobacco racial/ethnic disparities are not all due to SES gaps, but are, in part, due to smaller effects of SES indicators for Black and Hispanic populations; and (b) the racial and ethnic gap in tobacco use widens, rather than narrows, at the highest SES levels. As a result, this model suggests that there is a need to study racial/ethnic disparities in tobacco use across all SES levels, and the solution to tobacco disparities is beyond equal SES [34,35].

This study had two aims: firstly, to compare racial and ethnic groups for the associations between educational attainment and poverty status with cigarette smoking among American adults during pregnancy; and secondly, to explore the mediating effect of poverty status on such MDRs. Our hypotheses included: (1) educational attainment would be inversely associated with cigarette smoking in pregnant American women; (2) we expect a smaller protective effect of educational attainment on smoking during pregnancy for Black and Hispanic than Non-Hispanic White Americans, however; and (3) we expected the differential effect of educational attainment on smoking of pregnant women to be due to poverty status.

\section{Methods}

\subsection{Study Design}

This cross-sectional study is a secondary analysis of existing data. Data came from wave 1 of the Population Assessment of Tobacco and Health (PATH) adult data [36-38]. Wave 1 of the PATH data used here were collected between 2013 and 2014.

\subsection{Sample and Sampling of the PATH Study}

Participants were eligible for the PATH study if they were: (1) civilian; (2) noninstitutionalized; (3) a U.S. citizen; and (4) 18 years of age and older. We also limited this sample to those who reported that they were pregnant at the time of the survey. The PATH study sample was drawn with a four-stage probability sampling design [36-38].

\subsection{Analytical Sample of Pregnant Women in the Current Report}

The current analysis was limited to pregnant women at the time of the survey; therefore, the final analytical sample was 338 individuals.

\subsection{Variables}

The outcome was current smoking of cigarettes, measured with a self-reported assessment [39]. Confounders were age and region. Race and ethnicity were self-identified and operationalized as binary variables: Race (Black vs. White) and Ethnicity (Hispanic 
vs. Non-Hispanic). Age, a continuous variable, ranged from 1 to 7 : 1 for 18-24 years old, 2 for 25-34 years old, 3 for 35-44 years old, 4 for 45-54 years old, 5 for 55-64 years old, 6 for 65-74 years old, and 7 for $75+$ years old. Education was a six-level categorical variable: 1 for Less than High School, 2 for GED, 3 for High School Graduate, 4 for Some College (no degree) or associates degree, 5 for Bachelor's Degree, and 6 for Advanced Degree. The moderator was poverty status, measured as a dichotomous variable: (0) below the $200 \%$ federal poverty line, and (1) above the $200 \%$ federal poverty line.

Our outcome was current smoking (smoked 100 cigarettes and smokes currently) [39]. Current smoking and lifetime history of smoking 100 cigarettes were used in combination to define current smoking status. Participants were considered current smokers only if the answer to both questions was affirmative. The very same definition is commonly used in tobacco use research [40].

\subsection{Statistics and Data Analyses}

To analyze wave 1 of the PATH data, we used SPSS 23.0 (IBM Corp, Armonk, NY, USA). For the first step, we described our categorical and continuous variables. For this purpose, we used mean and frequency tables. For multivariable analysis, we applied three nested binary logistic regression models and had identical sample sizes. In our models, current smoking was the outcome, educational attainment was the independent variable, race and ethnicity were the moderators, and poverty status was the mediator. These logistic regression models were run without interactions or mediators (Model 1), with interactions but without the mediator (Model 2), and with interactions and the mediator (Model 3).

\subsection{Ethical Approval}

All the adults participating in the PATH study provided written informed consent. The study received Institutional Review Board (IRB) approval from Westat.

\section{Results}

\subsection{Descriptive Statistics}

This study included 338 pregnant American women. Most participants were NonHispanic $(n=273,80.0 \%)$ and White $(n=274,81.1 \%)$ (Table 1$)$.

Table 1. Descriptive statistics.

\begin{tabular}{lcc}
\hline & $\mathbf{n}$ & $\%$ \\
\hline Race & & \\
White & 274 & 81.1 \\
Black & 64 & 18.9 \\
Ethnicity & & \\
Non-Hispanic & 273 & 80.8 \\
Hispanic & 65 & 19.2 \\
Region & & \\
West & 39 & 11.5 \\
Northeast & 93 & 27.5 \\
Midwest & 127 & 37.6 \\
South & 79 & 23.4 \\
Poverty Status & & \\
Living in poverty & 229 & 72.9 \\
Living out of poverty & 85 & 27.1 \\
Current Smoker & & \\
Non-Smoker & 263 & 77.8 \\
Smoker & 75 & 22.2 \\
& Mean & SD \\
Age (1-7) & 1.57 & 0.67 \\
Educational Attainment (1-6) & 3.47 & 1.4 \\
\hline
\end{tabular}




\subsection{Pooled Sample Multivariable Models}

Table 2 shows the summary of three logistic regressions. Based on Model 1, there was an inverse correlation between education and the odds of current smoking among pregnant women. In this model, Blacks and Hispanics showed lower odds of current smoking, net of covariates. Model 2 showed significant interactions between race and ethnicity with educational attainment on current smoking status, suggesting that high educational attainment is more protective for Whites and Non-Hispanics than Blacks and Hispanics. Model 3, however, suggested that these interaction terms (MDR) are entirely due to poverty status. This was because the interaction terms were no more significant after poverty status was introduced to the model (Table 2).

Table 2. Summary of three logistic regression on current smoking models in the pooled sample.

\begin{tabular}{|c|c|c|c|c|c|c|}
\hline & B & SE & OR & $95 \% \mathrm{CI}$ & & $\bar{p}$ \\
\hline \multicolumn{7}{|l|}{ Model 1 (All) } \\
\hline Race (Blacks) & -1.10 & 0.42 & 0.33 & 0.15 & 0.75 & 0.008 \\
\hline Ethnicity (Hispanics) & -2.08 & 0.58 & 0.13 & 0.04 & 0.39 & 0.000 \\
\hline Country Region & & & & & & 0.274 \\
\hline South & 0.35 & 0.51 & 1.41 & 0.52 & 3.81 & 0.494 \\
\hline West & 0.32 & 0.50 & 1.38 & 0.52 & 3.65 & 0.515 \\
\hline Northeast & -0.54 & 0.61 & 0.58 & 0.18 & 1.92 & 0.372 \\
\hline Midwest & 1 & & & & & \\
\hline Age (10-Year Intervals) & 0.19 & 0.22 & 1.21 & 0.78 & 1.86 & 0.390 \\
\hline Educational Attainment (1-6) & -0.62 & 0.11 & 0.54 & 0.43 & 0.67 & 0.000 \\
\hline Constant & 0.77 & 0.65 & 2.15 & & & 0.237 \\
\hline \multicolumn{7}{|l|}{ Model 1 (All + Interaction) } \\
\hline Race (Blacks) & -3.15 & 1.01 & 0.04 & 0.01 & 0.31 & 0.002 \\
\hline Ethnicity (Hispanics) & -4.11 & 1.29 & 0.02 & 0.00 & 0.21 & 0.001 \\
\hline Country Region & & & & & & 0.266 \\
\hline South & 0.45 & 0.53 & 1.57 & 0.56 & 4.41 & 0.395 \\
\hline West & 0.34 & 0.51 & 1.41 & 0.52 & 3.86 & 0.502 \\
\hline Northeast & -0.49 & 0.63 & 0.61 & 0.18 & 2.10 & 0.435 \\
\hline Midwest & 1 & & & & & \\
\hline Age (10-Year Intervals) & 0.19 & 0.23 & 1.21 & 0.78 & 1.89 & 0.397 \\
\hline Educational Attainment (1-6) & -0.82 & 0.14 & 0.44 & 0.34 & 0.58 & 0.000 \\
\hline Black $\times$ Educational Attainment & 0.71 & 0.30 & 2.04 & 1.12 & 3.70 & 0.019 \\
\hline Hispanic $\times$ Educational & 0.75 & 0.38 & 2.12 & 1.00 & 4.51 & 0.050 \\
\hline Constant & 1.33 & 0.71 & 3.80 & & & 0.059 \\
\hline \multicolumn{7}{|l|}{$\begin{array}{l}\text { Model } 3 \text { (All + Interaction + } \\
\text { Mediator) }\end{array}$} \\
\hline Race (Blacks) & -2.42 & 1.05 & 0.09 & 0.01 & 0.70 & 0.021 \\
\hline Ethnicity (Hispanics) & -3.78 & 1.37 & 0.02 & 0.00 & 0.33 & 0.006 \\
\hline Country Region & & & & & & 0.253 \\
\hline South & 0.37 & 0.55 & 1.44 & 0.49 & 4.24 & 0.506 \\
\hline West & 0.18 & 0.53 & 1.20 & 0.42 & 3.42 & 0.736 \\
\hline Northeast & -0.66 & 0.65 & 0.52 & 0.14 & 1.84 & 0.307 \\
\hline Midwest & 1 & & & & & \\
\hline Age (10-Year Intervals) & 0.33 & 0.24 & 1.40 & 0.88 & 2.22 & 0.160 \\
\hline Educational Attainment (1-6) & -0.56 & 0.16 & 0.57 & 0.42 & 0.79 & 0.001 \\
\hline \multirow{4}{*}{$\begin{array}{l}\text { Black } \times \text { Educational Attainment } \\
\text { Hispanic } \times \text { Educational } \\
\text { Attainment } \\
\text { Living Out of Poverty } \\
\text { Constant }\end{array}$} & 0.40 & 0.32 & 1.50 & 0.81 & 2.78 & 0.201 \\
\hline & 0.66 & 0.41 & 1.94 & 0.86 & 4.35 & 0.110 \\
\hline & -2.15 & 0.66 & 0.12 & 0.03 & 0.43 & 0.001 \\
\hline & 0.80 & 0.78 & 2.22 & & & 0.304 \\
\hline
\end{tabular}

CI: Confidence Interval; SE: Standard Error; OR: Odds Ratio.

\section{Discussion}

The current study presents three findings. Firstly, overall, higher educational attainment is associated with lower odds of smoking among pregnant American women. Secondly, high educational attainment has smaller protective effects against Black and Hispanic smoking than pregnant White and Non-Hispanic women. Finally, the reason for this race and ethnic difference is that highly educated pregnant women are more likely to live in poverty, if Black and Hispanic. 
Our first finding is in harmony with the very well-established literature on the protective effect of social determinants of health and fundamental cause theory, which suggests that populations and individuals with higher SES, including education, avoid health risk behaviors $[13,14]$. This literature has shown that low education is a risk factor for tobacco use in pregnancy $[21,29,35,41]$. Extensive work by Marmot [42-45], Link and Phelan [46-48], Ross and Mirowsky $[13,14,49,50]$ and others [51] have shown SES as protective against risk behaviors such as tobacco.

Our second result on the MDRs of educational attainment on smoking status during pregnancy is in line with the literature on higher-than-expected risks of smoking and alcohol use in high SES (e.g., education, income, and employment) Blacks and Hispanics [34,35]. This finding is also in line with broader literature on the diminished returns of SES of a wide range of Blacks and Hispanics' outcomes than Whites [33]. MDRs are reported for the effects of educational attainment [52], income [53], employment [54], and marital status [55] on several health outcomes.

The third finding is also in line with a few studies which have proposed that income and poverty status may be the mechanism behind diminished educational attainment returns for Blacks [52]. However, we are not aware of any similar studies for Hispanics. In one study, MDRs of education on self-rated health were mediated by income, suggesting that labor market discrimination may be the cause of educational MDRs for Blacks [52]. One study showed that education has a smaller effect on bringing people out of poverty for Black than White individuals [56]. Similarly, educational attainment better predicts future raises of salary for White than Black people [57]. Upward social mobility is more difficult for Blacks than Whites [58]. As a result, eliminating discrimination in the U.S. labor market has become a priority for eliminating disparities, particularly those shaped by differential effects of education on health [52].

Another finding was lower odds of current smoking in pregnant Black and Hispanic women than pregnant White and Non-Hispanic women. The higher prevalence of smoking in Whites than Whites and Hispanics is well described in the literature [16-20]. Despite the protective (main) effects of race and ethnicity, we observed a differential effect of educational attainment on smoking of racial and ethnic groups, with pregnant Black and Hispanic women not gaining much from their educational attainment in terms of low smoking to pregnant White women. Other people have shown similar MDRs for some outcomes $[59,60]$.

There is a need to understand why educational attainment shows smaller effects on the behaviors of Blacks and Hispanics than Whites. One area that is still needed is research on the tobacco industry's predatory marketing practices in communities of color [61]. We have previously proposed that such marketing strategies may reduce SES's returns in terms of smoking for racial/ethnic minority people [34,35]. Here, we argue that such marketing practices may be responsible for the MDRs of education for pregnant women. People of color and residents of low SES environments report higher exposure to tobacco advertisements [62-64]. Thus, highly educated people in predominantly minority areas would still be disproportionately exposed to tobacco advertisements to a degree that is more than expected given their education. It is unknown whether more restrictive marketing policies that do not allow or at least reduce point-of-sale advertisements and flavoring tobacco products will reduce the smoking rates of people of color, and whether pregnant women would disproportionately benefit from such policies $[65,66]$. In other words, restricting predatory marketing may reduce tobacco use disparities by race, ethnicity, and SES. However, this hypothesis needs more research in the future [67].

At least some of the racial and ethnic tobacco disparities are beyond individuals' choices and shaped by social forces that marginalize Black and Hispanic people and increase their risk of tobacco exposure [68-71]. Among the well-described phenomena are that racial, ethnic, and low SES people are commonly targeted by predatory tobacco marketing practices $[63,72,73]$. Low SES individuals and racial and ethnic minorities are more frequently exposed to environmental tobacco risk factors, including, but not limited 
to, retail displays, coupons, discounts, and point-of-sale advertisements [61]. We have observed a high vulnerability of racial/ethnic populations across all SES levels [74], which may result in a more rapid transition of Black and Hispanic population from initiation to undesired outcomes, particularly because such populations have low access to and trust in cessation programs [75-77].

This study is not without methodological limitations. The cross-sectional design of our data does not allow causal inferences. The sample size was imbalanced across race and ethnic groups. Income, employment, marital status, and area-level SES were missing. We did not have information on the trimester of pregnancy. Finally, the sample size was low because the study was not conducted on pregnant women. To have a nationally representative sample, we used a national survey and selected only pregnant women. The study also only compared Blacks, Whites, and Hispanics. More research is needed on other ethnic groups such as Asian American, and Native Americans. Hispanics are a diverse group; therefore, there is a need to compare groups of Hispanics based on the country of origin. Despite these limitations, we believe that this study still makes a meaningful contribution to the literature.

\section{Conclusions}

In the United States, highly educated pregnant Black and Hispanic women stay at high risk of smoking due to a diminished educational attainment return on smoking risk. Disproportionately high risks of smoking in highly educated pregnant Black and Hispanic women are a threat because it is suggestive of high congenital disabilities and poor pregnancy outcomes of the next generation of middle-class Blacks and Hispanics. Health disparities are not a low SES problem because it extends to highly educated Blacks and Hispanics, who are the major growing sections of the U.S. population [78-81].

Author Contributions: S.A. acquired the funding, conceptualized the study, analyzed the data, prepared the first draft of the paper, revised the paper, and approved the final draft. S.B. conceptualized the study, revised the paper, and approved the final draft. Both authors have read and agreed to the published version of the manuscript.

Funding: Research reported in this publication was supported by the National Cancer Institute of the National Institutes of Health (NIH) and FDA Center for Tobacco Products (CTP) under Award Number U54CA229974. The content is solely the responsibility of the authors and does not necessarily represent the official views of the NIH or the Food and Drug Administration. Shervin Assari is also funded by the NIH under Awards U54MD008149, R25 MD007610, U54MD007598, and U54 TR001627, and CA201415-02.

Institutional Review Board Statement: The study received Institutional Review Board (IRB) approval from Westat.

Informed Consent Statement: All the adults participating in the PATH study provided written informed consent.

Data Availability Statement: Data are available online: https:/ / www.icpsr.umich.edu/web/NAHDAP / studies/36231 (accessed on 7 July 2021).

Conflicts of Interest: The authors declare no conflict of interest.

\section{References}

1. Savitz, D.A.; Dole, N.; Terry, J.W., Jr.; Zhou, H.; Thorp, J.M., Jr. Smoking and pregnancy outcome among African-American and white women in central North Carolina. Epidemiology 2001, 12, 636-642. [CrossRef]

2. Handler, A.; Davis, F.; Ferre, C.; Yeko, T. The relationship of smoking and ectopic pregnancy. Am. J. Public Health 1989, 79, 1239-1242. [CrossRef] [PubMed]

3. Hackshaw, A.; Rodeck, C.; Boniface, S. Maternal smoking in pregnancy and birth defects: A systematic review based on 173687 malformed cases and 11.7 million controls. Hum. Reprod. Update 2011, 17, 589-604. [CrossRef] [PubMed]

4. Zhang, D.; Cui, H.; Zhang, L.; Huang, Y.; Zhu, J.; Li, X. Is maternal smoking during pregnancy associated with an increased risk of congenital heart defects among offspring? A systematic review and meta-analysis of observational studies. J. Matern. Fetal Neonatal Med. 2017, 30, 645-657. [CrossRef] [PubMed] 
5. Brooke, O.G.; Anderson, H.R.; Bland, J.M.; Peacock, J.L.; Stewart, C.M. Effects on birth weight of smoking, alcohol, caffeine, socioeconomic factors, and psychosocial stress. BMJ 1989, 298, 795-801. [CrossRef] [PubMed]

6. Cunningham, J.; Dockery, D.W.; Gold, D.R.; Speizer, F.E. Racial differences in the association between maternal smoking during pregnancy and lung function in children. Am. J. Respir Crit. Care Med. 1995, 152, 565-569. [CrossRef] [PubMed]

7. Gray, R.; Bonellie, S.R.; Chalmers, J.; Greer, I.; Jarvis, S.; Kurinczuk, J.J.; Williams, C. Contribution of smoking during pregnancy to inequalities in stillbirth and infant death in Scotland 1994-2003: Retrospective population based study using hospital maternity records. BMJ 2009, 339, b3754. [CrossRef]

8. Land, G.H.; Stockbauer, J.W. Smoking and pregnancy outcome: Trends among black teenage mothers in Missouri. Am. J. Public Health 1993, 83, 1121-1124. [CrossRef]

9. Langley, K.; Rice, F.; van den Bree, M.B.; Thapar, A. Maternal smoking during pregnancy as an environmental risk factor for attention deficit hyperactivity disorder behaviour. A review. Minerva Pediatr. 2005, 57, 359-371.

10. Oken, E.; Levitan, E.B.; Gillman, M.W. Maternal smoking during pregnancy and child overweight: Systematic review and meta-analysis. Int. J. Obes. 2008, 32, 201-210. [CrossRef]

11. Stojanovic, M.; Bojanic, V.; Musovic, D.; Milosevic, Z.; Stojanovic, D.; Visujic, A.; Vucic, M.; Milosavljevic, I.; Vidanovic, M. Maternal smoking during pregnancy and socioeconomic factors as predictors of low birth weight in term pregnancies in Nis. Vojnosanit. Pregl. 2010, 67, 145-150. [CrossRef]

12. Mund, M.; Louwen, F.; Klingelhoefer, D.; Gerber, A. Smoking and pregnancy-A review on the first major environmental risk factor of the unborn. Int. J. Environ. Res. Public Health 2013, 10, 6485-6499. [CrossRef] [PubMed]

13. Mirowsky, J.; Ross, C.E. Education, Health, and the Default American Lifestyle. J. Health Soc. Behav. 2015, 56, 297-306. [CrossRef] [PubMed]

14. Ross, C.E.; Mirowsky, J. Refining the association between education and health: The effects of quantity, credential, and selectivity. Demography 1999, 36, 445-460. [CrossRef] [PubMed]

15. Montez, J.K.; Zajacova, A. Explaining the widening education gap in mortality among U.S. white women. J. Health Soc. Behav. 2013, 54, 166-182. [CrossRef]

16. Fichtner, R.R.; Sullivan, K.M.; Zyrkowski, C.L.; Trowbridge, F.L. Racial/ethnic differences in smoking, other risk factors, and low birth weight among low-income pregnant women, 1978-1988. MMWR CDC Surveill. Summ. 1990, 39, 13-21.

17. Hawkins, S.S.; Law, C.; Graham, H. Lifecourse influences on maternal smoking before pregnancy and postpartum among women from ethnic minority groups. Eur. J. Public Health 2010, 20, 339-345. [CrossRef]

18. Silveira, M.F.; Matijasevich, A.; Menezes, A.M.; Horta, B.L.; Santos, I.S.; Barros, A.J.; Barros, F.C.; Victora, C.G. Secular trends in smoking during pregnancy according to income and ethnic group: Four population-based perinatal surveys in a Brazilian city. BMJ Open 2016, 6, e010127. [CrossRef]

19. Troe, E.J.; Raat, H.; Jaddoe, V.W.; Hofman, A.; Steegers, E.A.; Verhulst, F.C.; Witteman, J.C.; Mackenbach, J.P. Smoking during pregnancy in ethnic populations: The Generation R study. Nicotine Tob. Res. 2008, 10, 1373-1384. [CrossRef]

20. Waterson, E.J.; Murray-Lyon, I.M. Alcohol, smoking and pregnancy: Some observations on ethnic minorities in the United Kingdom. Br. J. Addict. 1989, 84, 323-325. [CrossRef]

21. Ergin, I.; Hassoy, H.; Tanik, F.A.; Aslan, G. Maternal age, education level and migration: Socioeconomic determinants for smoking during pregnancy in a field study from Turkey. BMC Public Health 2010, 10, 325. [CrossRef]

22. Mohsin, M.; Bauman, A.E.; Forero, R. Socioeconomic correlates and trends in smoking in pregnancy in New South Wales, Australia. J. Epidemiol. Community Health 2011, 65, 727-732. [CrossRef] [PubMed]

23. Moussa, K.; Ostergren, P.O.; Grahn, M.; Kunst, A.E.; Eek, F.; Essen, B. Socioeconomic differences in smoking trends among pregnant women at first antenatal visit in Sweden 1982-2001: Increasing importance of educational level for the total burden of smoking. Tob. Control 2009, 18, 92-97. [CrossRef] [PubMed]

24. Najman, J.M.; Lanyon, A.; Andersen, M.; Williams, G.; Bor, W.; O'Callaghan, M. Socioeconomic status and maternal cigarette smoking before, during and after a pregnancy. Aust. N. Z. J. Public Health 1998, 22, 60-66. [CrossRef]

25. Silva, A.A.; Vasconcelos, A.G.; Bettiol, H.; Barbieri, M.A. Socioeconomic status, birth weight, maternal smoking during pregnancy and adiposity in early adult life: An analysis using structural equation modeling. Cad. Saude Publica 2010, 26, 15-29. [CrossRef] [PubMed]

26. Roberts-Clarke, I.; Morokoff, P.; Bane, C.; Ruggiero, L. Characteristics of smoking in low-income pregnant Latina and white women. J. Community Health Nurs. 2002, 19, 77-81. [CrossRef]

27. Poulsen, G.; Andersen, A.N.; Jaddoe, V.W.V.; Magnus, P.; Raat, H.; Stoltenberg, C.; Osler, M.; Mortensen, L.H. Does smoking during pregnancy mediate educational disparities in preterm delivery? Findings from three large birth cohorts. Paediatr. Perinat. Epidemiol. 2019, 33, 164-171. [CrossRef]

28. Kuntz, B.; Lampert, T. Social Disparities in Maternal Smoking during Pregnancy: Comparison of Two Birth Cohorts (1996-2002 and 2003-2012) Based on Data from the German KiGGS Study. Geburtshilfe Frauenheilkd. 2016, 76, 239-247. [CrossRef]

29. White, T.J.; Redner, R.; Skelly, J.M.; Higgins, S.T. Examining educational attainment, prepregnancy smoking rate, and delay discounting as predictors of spontaneous quitting among pregnant smokers. Exp. Clin. Psychopharmacol. 2014, 22, 384-391. [CrossRef] 
30. Ribeiro, V.S.; Figueiredo, F.P.; Silva, A.A.; Batista, R.L.; Barbieri, M.A.; Lamy Filho, F.; Alves, M.T.; Santos, A.M.; Bettiol, H. Do socioeconomic factors explain why maternal smoking during pregnancy is more frequent in a more developed city of Brazil? Braz. J. Med. Biol. Res. 2007, 40, 1203-1210. [CrossRef]

31. Nichter, M.; Nichter, M.; Muramoto, M.; Adrian, S.; Goldade, K.; Tesler, L.; Thompson, J. Smoking among low-income pregnant women: An ethnographic analysis. Health Educ. Behav. 2007, 34, 748-764. [CrossRef] [PubMed]

32. Jesse, D.E.; Graham, M.; Swanson, M. Psychosocial and spiritual factors associated with smoking and substance use during pregnancy in African American and White low-income women. J. Obstet. Gynecol. Neonatal Nurs. 2006, 35, 68-77. [CrossRef] [PubMed]

33. Assari, S. Unequal Gain of Equal Resources across Racial Groups. Int. J. Health Policy Manag. 2017, 7, 1-9. [CrossRef] [PubMed]

34. Assari, S.; Farokhnia, M.; Mistry, R. Education Attainment and Alcohol Binge Drinking: Diminished Returns of Hispanics in Los Angeles. Behav. Sci. 2019, 9, 9. [CrossRef]

35. Assari, S.; Mistry, R. Educational Attainment and Smoking Status in a National Sample of American Adults; Evidence for the Blacks' Diminished Return. Int. J. Environ. Res. Public Health 2018, 15, 763. [CrossRef] [PubMed]

36. Hyland, A.; Ambrose, B.K.; Conway, K.P.; Borek, N.; Lambert, E.; Carusi, C.; Taylor, K.; Crosse, S.; Fong, G.T.; Cummings, K.M.; et al. Design and methods of the Population Assessment of Tobacco and Health (PATH) Study. Tob. Control 2017, 26, 371-378. [CrossRef]

37. Tourangeau, R.; Yan, T.; Sun, H.; Hyland, A.; Stanton, C.A. Population Assessment of Tobacco and Health (PATH) reliability and validity study: Selected reliability and validity estimates. Tob. Control 2018. [CrossRef] [PubMed]

38. Chang, C.M.; Rostron, B.L.; Chang, J.T.; Corey, C.G.; Kimmel, H.L.; Sosnoff, C.S.; Goniewicz, M.L.; Edwards, K.C.; Hatsukami, D.K.; Wang, Y.; et al. Biomarkers of Exposure among U.S. Adult Cigar Smokers: Population Assessment of Tobacco and Health (PATH) Study Wave 1 (2013-2014). Cancer Epidemiol. Biomark. Prev. 2019, 28, 943-953. [CrossRef]

39. Ryan, H.; Trosclair, A.; Gfroerer, J. Adult current smoking: Differences in definitions and prevalence estimates-NHIS and NSDUH, 2008. J. Environ. Public Health 2012, 2012, 918368. [CrossRef]

40. King, B.A.; Dube, S.R.; Tynan, M.A. Current tobacco use among adults in the United States: Findings from the National Adult Tobacco Survey. Am. J. Public Health 2012, 102, e93-e100. [CrossRef]

41. Abdellatif, H.M. A number of variables, including age, education, smoking habits, and body mass index, are associated with the frequency of amalgam restorations in a Norwegian pregnant population. J. Evid. Based Dent. Pract. 2011, 11, 162-163. [CrossRef]

42. Marmot, M. Economic and social determinants of disease. Bull. World Health Organ. 2001, 79, 988-989. [PubMed]

43. Marmot, M. The Status Syndrome: How Social Standing Affects Our Health and Longevity; Bloomsbury Press: London, UK, 2004.

44. Marmot, M. Social determinants of health inequalities. Lancet 2005, 365, 1099-1104. [CrossRef]

45. Marmot, M.G.; Bell, R. Action on health disparities in the United States: Commission on social determinants of health. JAMA 2009, 301, 1169-1171. [CrossRef] [PubMed]

46. Link, B.G.; Phelan, J. Social conditions as fundamental causes of disease. J. Health Soc. Behav. 1995, 80-94. [CrossRef]

47. Link, B.G.; Phelan, J. The social shaping of health and smoking. Drug. Alcohol. Depend 2009, 104 (Suppl. 1), S6-S10. [CrossRef]

48. Clouston, S.A.P.; Link, B.G. A Retrospective on Fundamental Cause Theory: State of the Literature and Goals for the Future. Annu. Rev. Sociol. 2021, 47. [CrossRef]

49. Ross, C.E.; Mirowsky, J. Does employment affect health? J. Health Soc. Behav. 1995, 36, 230-243. [CrossRef] [PubMed]

50. Ross, C.E.; Mirowsky, J. The interaction of personal and parental education on health. Soc. Sci. Med. 2011, 72, 591-599. [CrossRef]

51. Guariguata, L.; Brown, C.; Sobers, N.; Hambleton, I.; Samuels, T.A.; Unwin, N. An updated systematic review and meta-analysis on the social determinants of diabetes and related risk factors in the Caribbean. Rev. Panam. Salud Publica 2018, 42, e171. [CrossRef] [PubMed]

52. Assari, S. Blacks' Diminished Return of Education Attainment on Subjective Health; Mediating Effect of Income. Brain Sci. 2018, 8, 176. [CrossRef] [PubMed]

53. Assari, S.; Hani, N. Household Income and Children's Unmet Dental Care Need; Blacks' Diminished Return. Dent. J. 2018, 6, 17. [CrossRef] [PubMed]

54. Assari, S. Whites but Not Blacks Gain Life Expectancy from Social Contacts. Behav. Sci. 2017, 7, 68. [CrossRef]

55. Assari, S.; Caldwell, C.H.; Zimmerman, M.A. Family Structure and Subsequent Anxiety Symptoms; Minorities' Diminished Return. Brain Sci. 2018, 8, 97. [CrossRef]

56. Assari, S. Parental Education Better Helps White than Black Families Escape Poverty: National Survey of Children's Health. Economies 2018, 6, 30. [CrossRef]

57. Assari, S.; Preiser, B.; Kelly, M. Education and Income Predict Future Emotional Well-Being of Whites but Not Blacks: A Ten-Year Cohort. Brain Sci. 2018, 8, 122. [CrossRef]

58. Assari, S. Parental Education Attainment and Educational Upward Mobility; Role of Race and Gender. Behav. Sci. 2018, 8, 107. [CrossRef] [PubMed]

59. Hudson, D.L.; Bullard, K.M.; Neighbors, H.W.; Geronimus, A.T.; Yang, J.; Jackson, J.S. Are benefits conferred with greater socioeconomic position undermined by racial discrimination among African American men? J. Mens Health 2012, 9, 127-136. [CrossRef]

60. Farmer, M.M.; Ferraro, K.F. Are racial disparities in health conditional on socioeconomic status? Soc. Sci. Med. 2005, 60, 191-204. [CrossRef] 
61. Anderson, S.J. Marketing of menthol cigarettes and consumer perceptions: A review of tobacco industry documents. Tob. Control 2011, 20 (Suppl. 2), ii20-ii28. [CrossRef]

62. Simon, P.; Camenga, D.R.; Morean, M.E.; Kong, G.; Bold, K.W.; Cavallo, D.A.; Krishnan-Sarin, S. Socioeconomic status and adolescent e-cigarette use: The mediating role of e-cigarette advertisement exposure. Prev. Med. 2018, 112, 193-198. [CrossRef] [PubMed]

63. Giovenco, D.P.; Spillane, T.E.; Merizier, J.M. Neighborhood differences in alternative tobacco product availability and advertising in New York City: Implications for health disparities. Nicotine Tob. Res. 2018. [CrossRef] [PubMed]

64. El-Toukhy, S.; Sabado, M.; Choi, K. Trends in Susceptibility to Smoking by Race and Ethnicity. Pediatrics 2016, 138. [CrossRef] [PubMed]

65. Nicksic, N.E.; Snell, L.M.; Barnes, A.J. Does Exposure and Receptivity to E-Cigarette Advertisements Relate to E-Cigarette and Conventional Cigarette Use Behaviors among Youth? Results from Wave 1 of the Population Assessment of Tobacco and Health Study. J. Appl. Res. Child. 2017, 8, 3.

66. Assari, S. Association of Educational Attainment and Race/Ethnicity With Exposure to Tobacco Advertisement Among US Young Adults. JAMA Netw. Open 2020, 3, e1919393. [CrossRef]

67. Soneji, S.; Knutzen, K.E.; Tan, A.S.L.; Moran, M.B.; Yang, J.; Sargent, J.; Choi, K. Online tobacco marketing among US adolescent sexual, gender, racial, and ethnic minorities. Addict. Behav. 2019, 95, 189-196. [CrossRef]

68. Unger, J.B.; Cruz, T.B.; Schuster, D.; Flora, J.A.; Johnson, C.A. Measuring exposure to pro- and anti-tobacco marketing among adolescents: Intercorrelations among measures and associations with smoking status. J. Health Commun. 2001, 6, 11-29. [CrossRef]

69. Brown-Johnson, C.G.; England, L.J.; Glantz, S.A.; Ling, P.M. Tobacco industry marketing to low socioeconomic status women in the U.S.A. Tob. Control 2014, 23, e139-e146. [CrossRef]

70. Lee, J.G.; Henriksen, L.; Rose, S.W.; Moreland-Russell, S.; Ribisl, K.M. A systematic review of neighborhood disparities in point-of-sale tobacco marketing. Am. J. Public Health 2015, 105, e8-e18. [CrossRef] [PubMed]

71. Moran, M.B.; Heley, K.; Pierce, J.P.; Niaura, R.; Strong, D.; Abrams, D. Ethnic and Socioeconomic Disparities in Recalled Exposure to and Self-Reported Impact of Tobacco Marketing and Promotions. Health Commun. 2019, 34, 280-289. [CrossRef]

72. Terry-McElrath, Y.M.; Wakefield, M.A.; Emery, S.; Saffer, H.; Szczypka, G.; O'Malley, P.M.; Johnston, L.D.; Chaloupka, F.J.; Flay, B.R. State anti-tobacco advertising and smoking outcomes by gender and race/ethnicity. Ethn. Health 2007, 12, 339-362. [CrossRef]

73. Keeler, C.; Max, W.; Yerger, V.; Yao, T.; Ong, M.K.; Sung, H.Y. The Association of Menthol Cigarette Use With Quit Attempts, Successful Cessation, and Intention to Quit Across Racial/Ethnic Groups in the United States. Nicotine Tob. Res. 2017, 19, 1450-1464. [CrossRef]

74. Greaves, L.; Hemsing, N. Women and tobacco control policies: Social-structural and psychosocial contributions to vulnerability to tobacco use and exposure. Drug Alcohol Depend. 2009, 104 (Suppl. 1), S121-S130. [CrossRef] [PubMed]

75. Cokkinides, V.E.; Halpern, M.T.; Barbeau, E.M.; Ward, E.; Thun, M.J. Racial and ethnic disparities in smoking-cessation interventions: Analysis of the 2005 National Health Interview Survey. Am. J. Prev. Med. 2008, 34, 404-412. [CrossRef] [PubMed]

76. Tran, S.T.; Rosenberg, K.D.; Carlson, N.E. Racial/ethnic disparities in the receipt of smoking cessation interventions during prenatal care. Matern. Child Health J. 2010, 14, 901-909. [CrossRef] [PubMed]

77. Trinidad, D.R.; Perez-Stable, E.J.; White, M.M.; Emery, S.L.; Messer, K. A nationwide analysis of US racial/ethnic disparities in smoking behaviors, smoking cessation, and cessation-related factors. Am. J. Public Health 2011, 101, 699-706. [CrossRef] [PubMed]

78. Orfield, M.; Luce, T.F. America's racially diverse suburbs: Opportunities and challenges. Hous. Policy Debate 2013, $23,395-430$. [CrossRef]

79. Landry, B. The New Black Middle Class; University of California Press: Berkeley, CA, USA, 1987.

80. Pattillo, M. Black Picket Fences: Privilege and Peril among the Black Middle Class; University of Chicago Press: Chicago, IL, USA, 2013.

81. Lacy, K.R. Blue-Chip Black: Race, Class, and Status in the New Black Middle Class; University of California Press: Chicago, IL, USA, 2007. 